\title{
CLASE: Chemistry Lessons Made Available to Students Electronically Using Voice Technology
}

\author{
Aster Vivien C. Vargas ${ }^{1}$ and Benilda Eleonor V. Comendador ${ }^{2+}$ \\ ${ }^{1}$ Dept. of Master of Science in Information Technology, Polytechnic University of the Philippines, Open \\ University System, Manila, Philippines \\ ${ }^{2}$ Open University Learning Management System, Polytechnic University of the Philippines, Sta. Mesa, \\ Metro Manila, Philippines
}

\begin{abstract}
The paper is about the development of an elearning system that will aid in the learning process and in storage management of student portfolios particularly in the Chemistry subject. The system contains voice technology such as audio library of the periodic table of elements and downloadable Text-to-Speech apps, uploading and storage of teacher's lessons in multimedia form, and viewing and uploading of student's video experiments using YouTube website as repository. The study made use of descriptive developmental method and prototyping to look for better solutions to enhance the existing traditional system. Findings revealed that the level of acceptance of the system is very acceptable in all aspects, thus these should be sustained by sourcing out funds to repair the unused and non-functional equipment, so that the efficacy of the system to the students and teachers would be very strong if this felt need is satisfied.
\end{abstract}

Keywords: elearning, chemistry online, audio library.

\section{Introduction}

Science education is one of the areas in education that needs greater attention considering the dismal performance of students from the Philippines in the comparative study among young population as to the science literacy and mathematical abilities of different countries. Young people are said to be the carriers and appreciators of science and technology (S\&T) in the future.

Results and perspectives from project ROSE (the Relevance of Science Education) indicate that many young people (YP) of developing countries opt for a career in S \& T (Sjoberg \& Schreiner, 2005), but in developed countries, declining recruitment is noticeable [1]. However, in recent years the same trend appears to be happening in the Philippines as evidenced by reducing enrolment in the science departments of large to medium-sized colleges and universities [2].

With the development of new technologies, e-Learning or eL (an abbreviated term for electronic learning) is observed to be gaining importance in Science, specifically in the Science Olympiad [3] and considered to be a tool providing students with personal education. As a process, eL is enabled by the use of Internet [4]. In the article titled "An Introduction to e-learning" in the University College of London website, e-learning is defined as the system of providing the means to facilitate the teaching-learning process such as teaching resources and activities online. Furthermore, one of the benefit that can be attributed to e-learning or ' $\mathrm{eL}$ ' is that it opens the way for teachers and students to interact more thereby improving the learning experience [5].

With the implementation of the K-to-12 educational system in the Philippines, the government has deemed basic education as compulsory [6]. This new system was designed to prepare would be graduates to

\footnotetext{
+ Corresponding author. Tel.: + 639204657683.

E-mail address: aster_vivien23@yahoo.com.
} 
be ready to enter the labour force and to be competitive and highly skilled. However, new challenges in science education are being addressed because of the implementation of this new educational system. Part of the problems identified was the lack of teaching materials [6]. At the initial implementation of K-to-12 education, teachers and administrators were in a frenzy trying to produce quality lecture materials, printing and photocopying modules to be distributed to the students. It is within this observation that the problems are rising as the Philippines implement the program that included the lack of government budget, classrooms and school supplies as well as the availability of teachers.

In the midst of these fundamental structural and curricular changes in the Philippines educational system, the challenge on how to keep up with the fast paced global development has to be addressed. Since one of the reasons why K-to-12 education was implemented is to ensure that the graduates are capacitated to compete in the global market, the surest way of keeping up with the rapid demand in workforce was to introduce IT/ICT in the teaching and learning process at the basic education.

At present, the education system is faced with the new challenge on how to deliver lessons in an efficient manner and at the same time promote learning through other multimedia means due to the evolving trends in education. The use of multimedia in education, as written by Jana Sosnowski in an online article, has progressed from audio cassettes to more interactive content such as images, videos, development of websites and the use of internet [7]. The article further stated that the use of images in multimedia in the classroom lessens the stress of reading too much text, helping students increase their memory retention [7].

In response to these developments in K-to-12 education as to the use and integration of IT/ICT in the teaching and learning, it was the intent of the study to contribute different ways to solve the problem related to IT/ICT integration by developing a system that will aid in learning process and in storage management of student portfolios.

The student portfolio is part of assessment in the recently introduced K-to- 12 curriculum program in the Philippine basic education [8]. Portfolios are believed to be authentic tools for assessment and help students demonstrate their learning progress [9]. And what better way to store them if not through online storage? There are advantages in using online storage rather than using external drives or using the hard disks of one's own personal computer. In the article titled "Top Ten Advantages of Using Online Storage Services" by Katie Nielsen, some of the benefits of storing online are lower cost, invisibility, meaning it doesn't use physical space, security, automation and accessibility [10].

This solution for the problem in the new education system can make sure that the system will result to a more engaging, learning motivated and easy to use system with IT/ICT. Hence, CLASE, which stands for Chemistry Lessons Made Available to Students Electronically using Voice Technology was developed to serve as an additional instructional tool to help teachers in delivering lessons specifically in General Chemistry. This system does not intend to replace the traditional classroom instruction because during the course of the inquiry, student readiness and the teachers' capability and the whole academic community were given consideration.

\section{The Developed System}

\subsection{System Architecture}

The system used the PHP to develop the interface which is in website form. MySQL was employed to handle the system's database.

All files such as lessons, and exercises uploaded by the faculty into the system are stored in the local database. These can be viewed and even downloaded by the students and faculty through the system web interface to their own PC. On the other hand, the students upload videos of their experiments in a separate website (in this case, it's the YouTube website) and only the links to these videos are stored in the system's database to avoid problems in big file sizes later on. These videos of the students doing their experiments will be part of their portfolio in their subject. The system provides a link to add to the user's browser the Select and Speak browser extension which only works online. The system also includes trial versions of downloadable apps such as Natural Reader, RZ Powerpoint Converter, and Acrobat Reader, all of which are freely offered in the internet. 
The system CLASE was deployed in an intranet setting where the database, application and web server were stored in a computer that functions as a server as shown in Fig. 1.

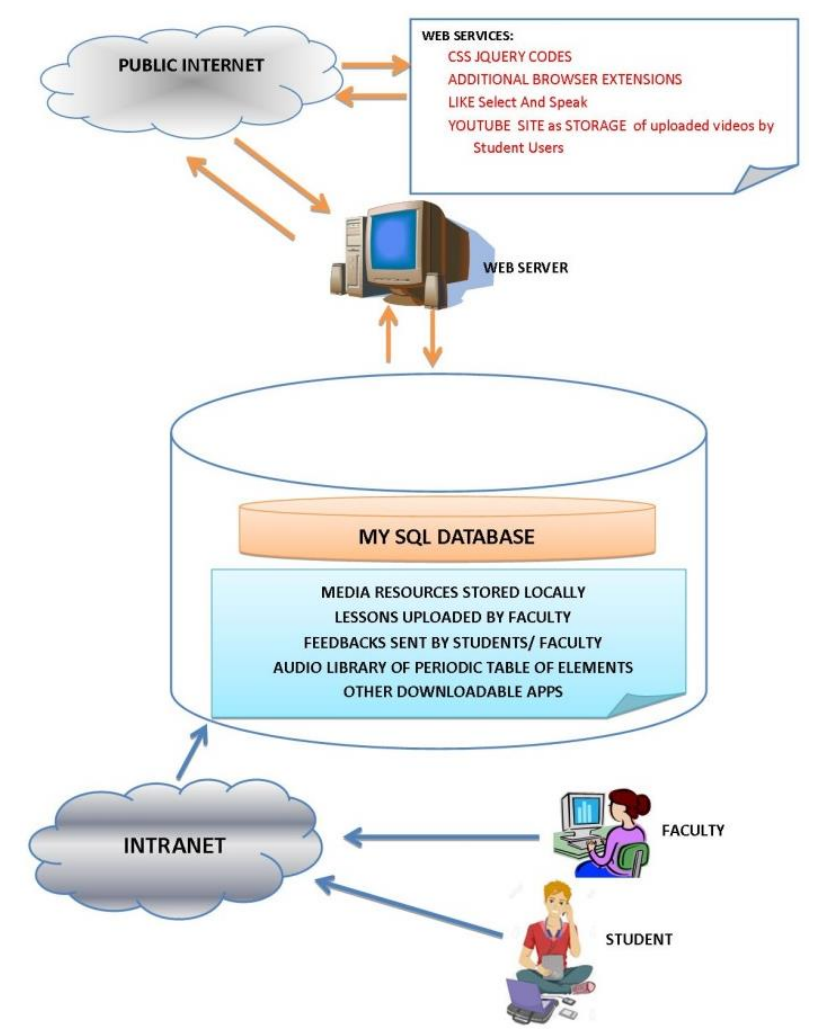

Fig. 1: System architecture of the system CLASE.

\subsection{System Features}

The system has two types of users namely faculty and student. The faculty enrolls to the system using their ID number as the username and providing their own password. Once the faculty has an account, he/she can start adding classes which is composed of the class name, description and schedules. Then the faculty can start adding students per class, providing them with a username and password which they'll use to access the system.

The system's primary features are on video uploading of faculty and students exercises using You Tube as storage; uploading of lessons by faculty in either PDF, word or PowerPoint format stored locally; viewing facility of uploaded videos, lessons, and exercises; an audio library of elements in the Periodic Table which can be updated/modified by the teacher and can be viewed by both types of user (faculty and student).

The system has provided a link to a downloadable applications such Acrobat Reader, Natural Reader that enable PDFs to be read aloud providing users with choices of what type of reader they prefer as well as reading speed; software like RZ PowerPoint Converter which converts presentation files to movies. The Natural Reader is added in the system to help in addressing the issues in reading skills. According to his article online, Ernest Balajthy wrote that there have been studies showing that using text-to-speech software has improved slow and struggling readers [11]. The system also provides a link to add to the user's browser the Select and Speak browser extension which only works online. However, this google chrome extension does not work in other browsers and is exclusive in google chrome browser only.

\section{Research Methods and Techniques}

The descriptive-developmental method was used in this study in order to establish an eLearning portal for teaching Chemistry for secondary schools. In the developmental part, the system was developed through prototyping. In prototyping, a prototype which is a sample model for the purpose of testing its usability and acceptability is developed in the hope of using it as basis of the final system [12]. It used gathered data and inputs from the target clientele using survey and class observation as well. Along with these, the hardware 
and software requirements for the implementation of the system were also considered before the development of the system prototype; then the prototype was tested and evaluated by the intended user.

For the descriptive part, the researcher conducted a survey with interviews if there is a need for clarifications to determine the feasibility and usability of the proposed system. The researcher also conducted internet and library researches to acquire information on the pros and cons of integrating eLearning in institutions.

There are two types of respondents of the survey. The first group belonged to the teachers composed of teachers with chemistry subject since this study was narrowed down to the Chemistry subject only. The second group of respondents is composed of 86 fourth year students belonging to the Science Technology and Engineering (STE) Class with consideration to their maturity in answering the set of questions. Since the group of teachers and students are manageable and they are the appropriate group who could satisfy the research questions, the population became the sample size of the study. This sampling technique is also called purposive sampling.

The researcher used the questionnaire as instrument for data gathering to determine the feasibility and usability of the proposed system. A Likert scale, as shown in Table 1 was used to measure the level of acceptance.

Table 1. Table of Likert Scale of Verbal Interpretation

\begin{tabular}{|c|c|c|c|}
\hline 1 & 2 & 3 & 4 \\
\hline $1.00-1.74$ & $.75-2.49$ & $2.50-3.24$ & $3.25-4.00$ \\
\hline Not Acceptable & $\begin{array}{c}\text { Slightly } \\
\text { Acceptable }\end{array}$ & Acceptable & $\begin{array}{c}\text { Very } \\
\text { Acceptable }\end{array}$ \\
\hline Very Weak & Weak & Strong & Very Strong \\
\hline
\end{tabular}

The study used descriptive statistics in order to answer the research questions. Frequency Count was used to determine the number of respondents who answered a particular item in every part of the research instrument. Weighted Mean was used to determine the level of acceptance in using CLASE in teaching Chemistry.

\section{Results and Discussion}

Findings revealed that the degree of seriousness of the issues encountered in teaching-learning process in Chemistry such as "lack of reference materials in Chemistry", "non-mastery of the topics in Chemistry", and "difficulty in preparing lessons for all the subjects" to name a few, obtained a general rating of "Serious".

The system obtained a general assessment of 'Very Acceptable' in all aspect. Specifically, the respondents gave the system's functionality the rating of 3.44, the system's reliability with 3.34 , its usability with 3.48 , efficiency with 3.46 , and the system's portability with 3.50 making this aspect the most highly acceptable of all criteria. The system also got a rating of 3.22 or 'Strong' with regards to the effect of implementing the system in the Chemistry subject.

\section{Conclusion and Future Works}

Based on the findings, the level of acceptance of the system is very acceptable in all aspects. These could be attributed to the fact that students and teachers are already looking forward to modernized approach to teaching and learning. Using the system can allow students to repetitively view a standard procedure until they feel they can do it by themselves. Repetition creates familiarity and although there is a saying that familiarity breeds contempt, the reality is that familiarity leads to liking in far more case than it does to contempt. The uploaded videos of themselves will enable students to critique their own work against a standard. This will help students learn not to rely on the teacher, to be responsible, and to be independent. Students will be taught digital literacy and will be provided with a mobile learning environment. In addition, making videos of themselves has aroused the interest of the students because they not learn to focus on doing 
the correct procedures in the lab experiments; they also had the chance to be creative and to show their skills in editing their videos.

As to the utility of the system, teacher respondents or end-users of the developed system can encourage sharing of resources, teachers will be benefited because more resources will become available to them. Teachers are given time to do additional or more important tasks than repeat a tiresome demonstration for a Chemistry procedure that the students can already view online. Furthermore, videos of chemical skills uploaded can be used by teachers in determining key areas in laboratory skills to be enhanced. Since the portfolios are electronically available, teachers can check outputs of students at their convenience.

While the conversion from the traditional system into a high-tech system of teaching and learning may not happen at once, gradually, studies such as this could serve as the initiator to change. Therefore these should be sustained by sourcing out funds to repair the unused and non-functional equipment so that the efficacy of the system CLASE to the students and teachers would be very strong if this felt need is satisfied.

Further studies should be done to include other subject areas and such research should be funded and supported by the Department of Education. This could very well be a breakthrough for an enhanced teaching-learning process in all subject areas.

\section{Acknowledgements}

The first author thanks her colleagues, and Prof. Benilda Eleonor V. Comendador for the insights, inputs and support.

\section{References}

[1] Sjoeberg, Svein (2005, January) How do Learners in Different Cultures Relate to Science and Technology: Global Patterns in Student's Views of Science and Interest in Science (cited) Retrieved October 12, 2015 from https://www.researchgate.net/publication/26453386_How_do_learners_in_different_cultures_relate_to_science_a nd_technology

[2] Suarez, KD. (2012, June). 'Unpopular Courses: The road less travelled. Retrieved: November 22, 2015 from http://www.rappler.com/nation/7394-the-less-popular-route

[3] Can, M.H. 2015. An Investigation Of Teacher's Use Of Elearning In Science Olympiad In Russian Schools. Procedia - Social and Behavioral Sciences 191 (2015) $241-249$.

[4] Nagi, K., Firouz, A., \& Suesawaluk, P. (2007). eLearning in Thailand - A Survey of Social. Paper presented at the TENCON 2007 - 2007 IEEE Region 10 Conference, Bangkok.

[5] An Introduction to e-learning. Retrieved November 12, 2015 from https://www.ucl.ac.uk/teaching-learning/casestudies-news/e-learning

[6] “Why does the Philippines Need the K-12 Education System?”, http://www.cianeko.hubgapges.com/hub/TheImplementation-of-the-K-12-Program-in-the-Philippine-Basic-Education-Curriculum retrieved: August 21, 2013

[7] Advantages and Disadvantages of Schools Using Multimedia. Retrieved: October 10, 2015 from http://education.seattlepi.com/advantages-disadvantages-schools-using-multimedia-3099.html

[8] The K to 12 Basic Education Program. Retrieved June 10, 2015 from http://www.donboscopress.ph/wpcontent/uploads/2012/06/DepEd-K12-Basic-Education.pdf

[9] Portfolio. Retrieved October 7, 2015, from https://www.teachervision.com/assessment/teachingmethods/20153.html

[10] Top Ten Advantages of Using Online Storage Services. Retrieved: December 10, 2016 from http://online-storageservice-review.toptenreviews.com/top-ten-advantages-of-using-online-storage-services.html

[11] Text-to-Speech Software for Helping Struggling Readers. Retrieved: July 22, 2015 from http://webzoom.freewebs.com/sallydoxie/TTS.pdf

[12] Prototype. Retrieved: August 13, 2015 from https://en.wikipedia.org/wiki/Prototype 